\title{
Modelling Carbon Fluxes as an Aid to Understanding Perennial Ryegrass (Lolium perenne) Root Dynamics
}

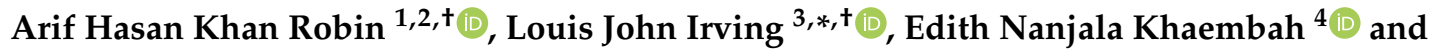 \\ Cory Matthew ${ }^{1}$ \\ 1 School of Agriculture and Environment PN433, Massey University, Private Bag11-222, \\ Palmerston North 4442, New Zealand; gpb21bau@bau.edu.bd (A.H.K.R.); c.matthew@massey.ac.nz (C.M.) \\ 2 Department of Genetics and Plant Breeding, Bangladesh Agricultural University, \\ Mymensingh 02202, Bangladesh \\ 3 Faculty of Life and Environmental Sciences, University of Tsukuba, Tsukuba 305-8577, Japan \\ 4 The New Zealand Institute for Plant \& Food Research Limited, Private Bag 4704, Christchurch Mail Centre, \\ Christchurch 8140, New Zealand; edith.khaembah@plantandfood.co.nz \\ * Correspondence: irving.louis.fb@u.tsukuba.ac.jp; Tel.: +81-(0)29-853-4777 \\ + These authors contributed equally to this work.
}

Received: 12 September 2018; Accepted: 22 October 2018; Published: 24 October 2018

\begin{abstract}
Despite the importance of roots in determining plant performance, the factors controlling their development and longevity remain poorly understood. Grass morphology is based on repeating units called phytomers, with each capable of producing one leaf, one daughter tiller, and one or more roots. We developed a phytomer-based understanding of root birth, growth and senescence in Lolium perenne, using a modeling approach to explore seasonal effects on root turnover dynamics, and to explore cultivar differences in these processes. Similar to leaves, roots exhibit a clear progression from initiation, growing for approximately seven phyllochrons, with growth rates strongly influenced by environmental conditions. In spring, the phyllochron decreased over the experiment, while it increased in autumn. In spring, $C$ availability exceeding maintenance respiratory requirements allowed root growth at each phytomer position, with a 70/30 split between maintenance and growth. Under C-deficient conditions in autumn, this split was approximately 80/20, with growth limited to younger phytomer positions, while older roots were more susceptible to starvation-induced senescence due to their high $\mathrm{C}$ requirements for maintenance respiration.
\end{abstract}

Keywords: ryegrass; phytomer; rhizochron; root growth; respiration; model

\section{Introduction}

Roots allow the efficient uptake of water and nutrients from soils and are important contributors to plants' ability to compete successfully for resources. In contrast to leaf turnover [1,2], root dynamics receive comparatively little attention, in part due to the difficulty of performing measurements of roots growing in soil. Roots are of fundamental importance to plant growth and development, and their respiratory fluxes are an important component of plant carbon (C) economy. Although at a broad level allometric scaling laws can be used to estimate root mass based on aboveground tissue mass [3], individual plants exhibit a great degree of plasticity in their biomass allocation and are strongly influenced by environmental factors.

Plant growth rates are strongly contingent on environmental conditions. Photosynthesis is the ultimate $\mathrm{C}$ source for growth, and exhibits a strong seasonality [4,5]. Factors influencing whole plant $\mathrm{C}$ gain also mediate root growth; for example, roots comprised up to $50 \%$ of dry weight in tall fescue grown under high light conditions, but only 20\% under low light conditions [6]. Fulkerson and 
Donaghy [7] noted a strong relationship between daily solar radiation and plant water soluble carbohydrate concentrations, which they consider the primary $\mathrm{C}$ source for root and leaf regrowth post-defoliation. In an ecological study of the effects of soil warming on upland grasslands, root birth rate correlated with photosynthetically active radiation, while death rates correlated with vegetation temperature [8]. Isotope labeling studies have shown that the majority of $C$ for new growth was fixed within the previous two days $[9,10]$, and a close relationship between daily photosynthesis and root respiration established, with the majority of respired C deriving from same day photosynthesis [11].

Root growth is strongly seasonal [12,13], but is also mediated by other factors: drought [14], salinity [15] and osmotic stress [16] limit growth, while root proliferation is common in nutrient-rich patches [17]. These types of exogenous factors add a layer of complexity to the underlying systemic patterns of root initiation, growth, and senescence, making an understanding of the fundamental processes more difficult. Studying root growth in soils is difficult, even if we could avoid all the aforementioned issues, the recovery of whole, complete root systems is technically demanding. Hydroponic culture represents a simple method to resolve both problems by growing plants under standard, uniform conditions, where roots can be retrieved without substantial loss, either as a result of mechanical forces or biotic damage, albeit a highly artificial system with little correspondence to the real-world conditions experienced by plants in the field.

Perennial ryegrass (Lolium perenne L.) is a widely used temperate forage grass worldwide. It is hardy, establishes well, and has a high palatability for ruminant animals. Grass plant morphology is based on the tiller axis, which is comprised of segments, called phytomers. Phytomers are produced by the apical meristem, with each phytomer capable of producing one leaf, one daughter tiller, and generally two roots. The tiller axis represents an age gradient, with newly formed phytomers at the tip, followed by around six immature phytomers, before the first leaf-bearing phytomer [18]. Ryegrass is typically considered as a "three-leaf" plant, with one newly expanding leaf, two fully expanded leaves, while the oldest, fourth leaf, begins to senesce [7]. Root initiation typically occurs at the phytomer bearing the senescent leaf, although there is some variability in this [18]. The youngest roots are found on phytomers proximate to the leaves, with progressively older roots further from the growing point. However, while the situation for leaves is well-characterized, a mechanistic understanding of root initiation, growth, and senescence is currently lacking. Previous studies tend to treat the roots as a homogenous population, often characterizing them by their position in the soil profile (e.g., [12,19]), with little consideration of how root age or tiller axis position may affect their function.

In this paper, we have three main goals (1) to develop a phytomer-based understanding of root birth, growth and senescence, (2) to explore the effects of season on the dynamics of these processes, and (3) to explore cultivar differences in these processes. To achieve these goals, two cultivars of perennial ryegrass, 'Alto' a New Zealand bred, endophytic cultivar [20] and 'Aberdart' a United Kingdom bred, non-endophytic, high sugar cultivar [21,22] were grown hydroponically in a glasshouse experiment over the transition from autumn to winter (autumn experiment) or from winter to spring (spring experiment). These two cultivars were selected as the most diverse germplasm available, in order to explore genetic plasticity in root growth. As a potential way to gain previously unavailable insight, we took observations on the dry weights of progressively older roots at successive phytomers on ryegrass tiller axes, with a known time interval between formation of successive roots, and constructed a mathematical model based on root mass data for successive phytomers to describe the root formation processes underlying the data.

\section{Materials and Methods}

\subsection{Experimental}

Plants were grown hydroponically in a glasshouse at the Massey University Plant Growth Unit, Palmerston North, New Zealand (latitude $40^{\circ} 19^{\prime}$ South, longitude $174^{\circ} 46^{\prime}$ East, altitude 25 
masl). Two separate experiments were conducted, a spring experiment and an autumn experiment. The spring experiment ran from 1 July 2008 to 28 September 2008, and the autumn experiment from 3 March 2009 to 31 May 2009. In the spring experiment, the plants experienced increasing day length, while in the autumn experiment the plants experienced decreasing day length.

Two late flowering diploid Lolium perenne cultivars; perennial ryegrass, 'Alto' a New Zealand bred, endophytic cultivar and 'Aberdart' a United Kingdom bred, non-endophytic, high sugar cultivar were used. To provide a population of plants for study, in each experiment, 10 plants (genotypes) from established field swards of each cultivar were uplifted, brought to the laboratory, and adult tillers divided out from each plant to provide six clonal replicates of each genotype to transplant into the hydroponic unit. Any small daughter tillers attached to tillers at transplanting were removed. Tiller length measured from the pseudostem base to the leaf tip was 10-15 cm at transplanting. The hydroponic unit comprised 20 trays, each holding 12 plants spaced at $12 \mathrm{~cm} \times 12 \mathrm{~cm}$. Individual tillers were supported by polystyrene sheets with $2 \mathrm{~cm}$ diameter holes, in which plants were suspended using sponge rubber wads. During the growing period, only the parent tiller and first two daughter tillers were allowed to develop, with all other daughter tillers removed upon appearance. Leaf appearance was recorded throughout both experiments. In this way, when plants were dissected at the end of the experiment and each live leaf and root assigned a phytomer position on the tiller axis, the age of each phytomer and its phyllochron could be determined from the leaf appearance data. The details of hydroponic culture, composition of nutrient solution and plant management are described in a previous publication [23].

\subsection{Photosynthesis Measurement}

The leaf appearance dates for all measured tillers were recorded, so it was possible to calculate the leaf appearance rate (phyllochron). The lengths and widths of live leaves were recorded and the area of individual leaves was calculated using a form factor [24] following the equation: $0.7 \times$ lamina length $(\mathrm{cm}) \times$ width $(\mathrm{cm})$. Net $\mathrm{CO}_{2}$ exchange rate was measured using a CIRAS-2 Portable Photosynthesis System (PP Systems, Amesbury, MA, USA) with the leaf provided 420 ppm $\mathrm{CO}_{2}, 1000 \mu \mathrm{mol} \mathrm{m} \mathrm{m}^{-2} \mathrm{~s}^{-1}$ PPFD (photosynthetic photon flux density) at ambient temperature. Photosynthesis measurements were conducted 74 and 30 days after transplanting in the spring and autumn experiments, respectively. These days were selected as the day lengths were equal. The photosynthetic capacities of the five youngest leaves of two clonal replicates of six genotypes for each cultivar in the spring experiment and those of three clonal replicates of five genotypes for each cultivar in the autumn experiment were measured. The youngest emerging leaf was taken as a reference point and denoted leaf position 1 . Thus, net $\mathrm{CO}_{2}$ exchange rate of a total of 270 leaves from 54 tillers was recorded. Leaf lamina length $(\mathrm{cm})$, and width (nearest $0.5 \mathrm{~mm}$ ) were recorded on the day of photosynthesis measurement for the respective leaf positions. Leaf area inside the cuvette was calculated as: leaf lamina width at the mid-point between the tip and the ligule $\times$ leaf length inside the cuvette (cuvette length was $10 \mathrm{~cm}$ ).

\subsection{Root Data Collection}

Isolation of individual roots was facilitated by initially floating in a bucket of water the tiller base and attached roots of each plant being dissected. Further details of root data collection were described in a previous publication [23]. The number of plants dissected in the spring experiment was 30 (10 genotypes $\times 3$ clonal replicates) for Aberdart, and 27 (9 genotypes $\times 3$ clonal replicates) for Alto because three plants failed to establish. Due to the larger size of the plants and the increased time required for processing, in the autumn experiment 16 plants (8 genotypes $\times 2$ clonal replicates) of each cultivar were dissected. After dissection roots were placed in a drying oven for $48 \mathrm{~h}$ at $60^{\circ} \mathrm{C}$, then weighed to determine dry mass. 


\subsection{Theoretical}

A model based on an exponential rise to a maximum (Equation (1)) was fitted to a plot of root mass data against time, where $\mathrm{R}$ was the root mass in $\mathrm{mg}$, $\mathrm{m}$ is the maximum root mass achieved at a fully mature phytomer, $k$ is the gradient of the curve, and $t$ is the age (days) of the phytomer position. The regression line and 95\% confidence intervals were returned by Graphpad Prism version 7 for Windows (Graphpad Software, La Jolla, CA, USA).

$$
R=m\left(1-e^{-k t}\right),
$$

It was noted that the data points for the oldest roots often fitted the regression curve poorly, sometimes lying above and sometimes below the curve. Possible reasons include senescence, additional substrate supply from daughter tillers [25] or variability in plant size when the oldest roots were formed. For this reason, we excluded data points from older roots (Figure 1). The modelled data spanned 56 and 53 days in spring, and 57 and 59 days in autumn for Alto and Aberdart respectively. Under these conditions, our exponential model fitted the root data to a high degree (Figure $1 ; P<0.001$, $r^{2}>0.85$ in all cases). All datasets passed a Shapiro-Wilks test for normality, and a runs test for data deviation from the model.

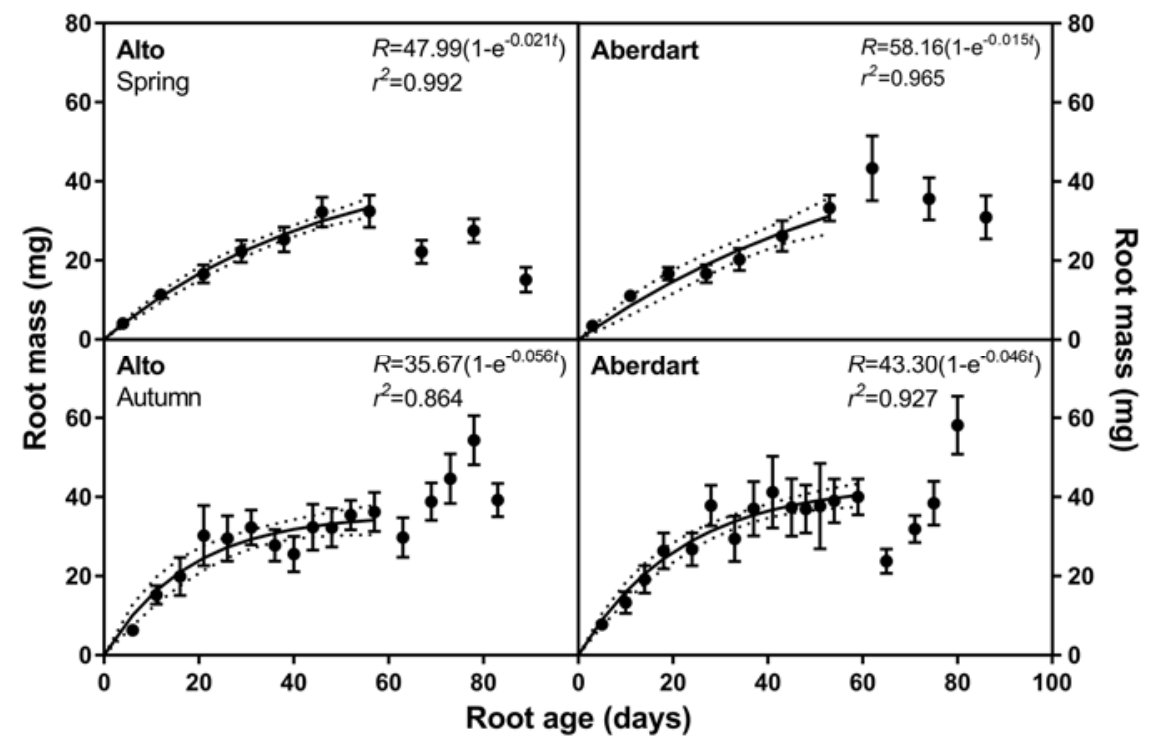

Figure 1. Mean root masses $( \pm \mathrm{SE})$ with an exponential rising to a maximum model $( \pm 95 \% \mathrm{CI})$.

Root mass at each phytomer position was estimated from the fitted curve and used to estimate the $C$ requirements for growth and maintenance respiration. Curve confidence interval data were used to estimate error terms associated with growth and respiration values. Daily root growth $(G$, Equation (2)) was estimated as the differences in mass between two adjacent phytomer positions $\left(W_{1}\right.$ and $\left.W_{0}\right)$, divided by the difference in root age between the two positions $\left(a_{1}-a_{0}\right)$ assuming that the age difference between roots was equal to the leaf appearance rates [23].

$$
\begin{gathered}
G=\frac{\left(W_{1}-W_{0}\right)}{\left(a_{1}-a_{0}\right)}, \\
\text { Construction }=(G \times 0.4)+(G \times 0.24), \\
\text { Maintenance }=0.02 \times \frac{\left(W_{1}-W_{0}\right)}{2},
\end{gathered}
$$

Root construction costs (mg C mg ${ }^{-1}$ dry weight (DW) day ${ }^{-1}$ ) were estimated according to Equation (3), where the daily root growth $(G)$ was multiplied by the root $C$ content (assumed to be 
$\left.0.4 \mathrm{mg} \mathrm{C} \mathrm{mg}^{-1} \mathrm{DW}\right)$, and its construction cost $\left(0.24 \mathrm{mg} \mathrm{C} \mathrm{mg}^{-1} \mathrm{DW}\right)$ [26]. Maintenance respiration was calculated according to Equation (4) as the average dry weight between two adjacent phytomer positions multiplied by $0.02 \mathrm{mg} \mathrm{C} \mathrm{mg}^{-1} \mathrm{DW}_{\text {day }}{ }^{-1}$.

\subsection{Photosynthetic Carbon Fixation and Distribution}

The mean photosynthetic rates of five young leaves measured during the experiment was multiplied by the leaf area of the youngest five leaves measured at the destructive harvest. The photosynthetic rate of older leaves was estimated by multiplying their recorded area by $75 \%$ of the mean photosynthetic rate of the younger leaves. Photosynthetic rates are known to decrease with leaf age, and this $75 \%$ weighting factor was selected to account for age-related declines in photosynthesis. To estimate daily photosynthetic uptake, the calculated whole tiller photosynthesis rate was multiplied by the photoperiod on the last day of each experiment; $12 \mathrm{~h}$ in the spring experiment and $9 \mathrm{~h}$ in the autumn experiment, based on sunrise and sunset times for the latitude and dates. We assumed that $15 \%$ of fixed $C$ was allocated to the roots [27], and that this was distributed acropetally between phytomer positions. The $\mathrm{C}$ available at any given phytomer $(P)$ was calculated as the $\mathrm{C}$ available at the preceding phytomer position $(P-1)$, minus the $C$ costs of maintenance and construction respiration costs for the roots at that position (Equation (5)). The initial $C$ availability $\left(C_{0}\right)$ was reported in Table 1 .

$$
C_{P}=C_{(P-1)}-(\text { Construction }+ \text { Maintenance }),
$$

Errors were estimated based on the sum of the estimated errors for root construction and maintenance.

\subsection{Data Analysis}

Data was analyzed using a $2 \times 2$ factorial ANOVA for cultivar $\times$ season comparisons and $t$-tests for pairwise comparisons in IBM SPSS for Windows version 24.0 (International Business Machines Corporation, Armonk, NY, USA).

\section{Results}

Aberdart produced a $53.4 \%$ higher leaf area than Alto in the spring experiment, and a $49.8 \%$ higher area in the autumn experiment $(P<0.001$; Table 1$)$. Alto and Aberdart leaf areas were $85.3 \%$ and $81.0 \%$ higher in the autumn experiment than the spring experiment $(P<0.001)$. Alto exhibited a higher photosynthetic rate than Aberdart $(P<0.001)$, but no effect of season was noted $(P=0.497)$. Assuming $12 \mathrm{~h}$ and $9 \mathrm{~h}$ daylengths in the spring and autumn experiments, and a $15 \% \mathrm{C}$ flux to the roots, photoassimilate supply to the roots was approximately $3 \mathrm{mg} \mathrm{day}^{-1}$ higher in Aberdart than Alto, and around $25 \%$ higher in the autumn than the spring experiments. Leaf area was the primary driver of these differences in both cases, with photosynthetic rates less important.

Table 1. Photosynthetic parameters of Alto and Aberdart in spring and autumn $( \pm \mathrm{SE})$.

\begin{tabular}{|c|c|c|c|c|c|c|c|}
\hline & \multicolumn{2}{|c|}{ Spring } & \multicolumn{2}{|c|}{ Autumn } & \multicolumn{3}{|c|}{$p$-Value } \\
\hline & Alto & Aberdart & Alto & Aberdart & Season & Cultivar & $\mathrm{S} \times \mathrm{C}$ \\
\hline Leaf area $\left(\mathrm{cm}^{2}\right.$ plant $\left.^{-1}\right)$ & $62.6(3.3)$ & $96.0(4.9)$ & $116.0(6.5)$ & $173.8(5.9)$ & $<0.001$ & $<0.001$ & 0.021 \\
\hline Leaf number (leaves plant ${ }^{-1}$ ) & $6.63(0.13)$ & $8.10(0.15)$ & $8.69(0.30)$ & $12.25(0.47)$ & $<0.001$ & $<0.001$ & $<0.001$ \\
\hline Photosynthetic rate $\left(\mathrm{mmol} \mathrm{CO}_{2} \mathrm{~m}^{2} \mathrm{~s}^{-1}\right)$ & $16.4(0.6)$ & $15.3(0.5)$ & $16.3(0.5)$ & $14.7(0.4)$ & 0.497 & 0.005 & 0.582 \\
\hline Assumed daylength $(\mathrm{h})$ & 12 & 12 & 9 & 9 & & & \\
\hline Root $C$ supply $\left(C_{0} ;\right.$ mg $C$ plant $^{-1}$ day $\left.^{-1}\right)$ & 7.6 & 10.6 & 10.0 & 12.6 & & & \\
\hline
\end{tabular}

While the data quality was insufficient for the curve fitting software to determine reliable estimates of the maximum root mass values, the exponent $\mathrm{k}$ was lower in the spring than the autumn plants (Figure 1 ; spring; $k=0.021(95 \% \mathrm{CI} ; \pm 0.004)$ and $0.015( \pm 0.008)$; autumn $k=0.056( \pm 0.012)$ and 0.046 $( \pm 0.007)$ for Alto and Aberdart, respectively), which would relate to a lower root growth rate. In the 
autumn experiment, the majority of root growth occurred in the youngest half of phytomer positions (Figure 1), with no difference in root mass noted between phytomers six and 12 for Alto $(P=0.558)$ or six and 14 for Aberdart $(P=0.752)$, suggesting that the older roots were not growing. By contrast, in spring, the roots grew at each phytomer position, which may suggest that under these conditions a factor other than $C$ availability mediated growth rate. During the spring experiment, the phyllochron decreased in progressively younger roots, while in autumn the opposite pattern could be seen with progressively longer phyllochrons at younger positions (Table 2).

Table 2. Phyllochron of Alto and Aberdart in spring and autumn $( \pm \mathrm{SE})$.

\begin{tabular}{ccccc}
\hline Phytomer & Alto-Spring & Aberdart-Spring & Alto-Autumn & Aberdart-Autumn \\
\hline 2 & $7.1(0.2)$ & $6.1(0.2)$ & $8.7(0.5)$ & $7.7(0.6)$ \\
3 & $8.2(0.2)$ & $7.1(0.2)$ & $7.7(0.4)$ & $6.6(0.4)$ \\
4 & $7.4(0.3)$ & $6.8(0.2)$ & $7.6(0.4)$ & $5.7(0.4)$ \\
5 & $7.6(0.3)$ & $7.2(0.3)$ & $5.6(0.3)$ & $5.4(0.3)$ \\
6 & $8.1(0.3)$ & $7.3(0.4)$ & $5.4(0.2)$ & $4.8(0.4)$ \\
7 & $8.7(0.3)$ & $8.1(0.4)$ & $4.9(0.2)$ & $4.6(0.3)$ \\
8 & $8.6(0.5)$ & $7.6(0.4)$ & $5.1(0.2)$ & $4.4(0.2)$ \\
9 & $9.2(0.4)$ & $8.5(0.5)$ & $4.9(0.2)$ & $4.3(0.3)$ \\
10 & $9.9(0.6)$ & $8.8(0.4)$ & $4.6(0.3)$ & $5.5(0.4)$ \\
11 & & & $4.9(0.2)$ & $4.5(0.3)$ \\
12 & & $4.6(0.2)$ & $4.5(0.3)$ \\
13 & & $4.5(0.2)$ & $4.3(0.2)$ \\
14 & & $4.3(0.2)$ & $4.5(0.2)$ \\
15 & & $4.3(0.2)$ & $4.2(0.2)$ \\
16 & & & $3.5(0.3)$ & $4.2(0.2)$ \\
\hline
\end{tabular}

Alto showed a greater range of phyllochron values between seasons than did Aberdart, which may suggest a greater seasonality. No difference in the root mass at the oldest phytomer position included in the model was noted either between cultivars $(P=0.627)$, or season $(P=0.248)$; nor was there any interaction $(P=0.692)$. Photoassimilate supply decreased approximately linearly with phytomer position, reaching zero at around phytomer 11 or 12 in the autumn experiment (Figure 2).
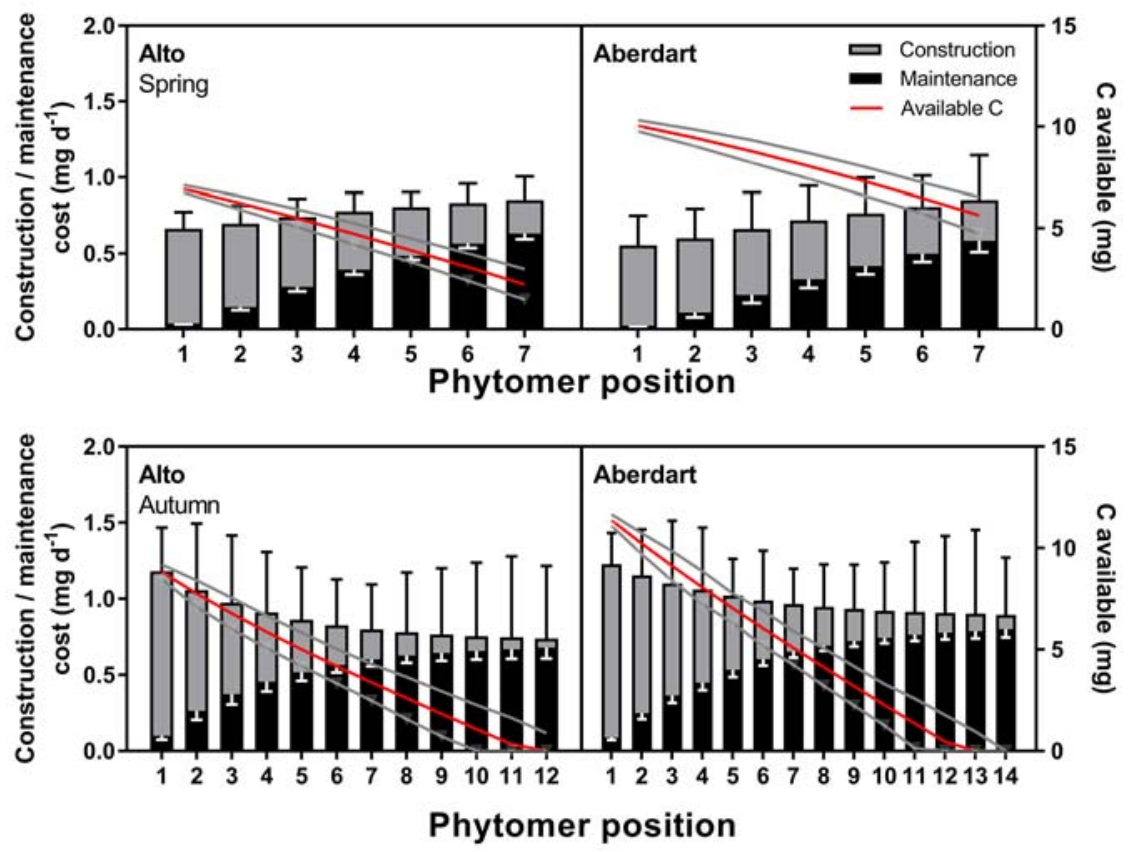

Figure 2. $\mathrm{C}$ costs and availability for root growth and maintenance in Alto and Aberdart $( \pm 95 \% \mathrm{CI})$. 
The calculated respiration rates, inclusive of both construction and maintenance components, for Alto in spring and autumn were 0.025 and $0.024 \mathrm{mg} \mathrm{C} \mathrm{mg}^{-1}$ day ${ }^{-1}$ respectively, with maintenance respiration accounting for $71 \%$ and $79 \%$ of the total respiration. In Aberdart, those figures were 0.026 and $68 \%$ in spring, and $0.024 \mathrm{mg} \mathrm{C} \mathrm{mg}^{-1}$ day $^{-1}$ and $79 \%$ in autumn. Maintenance respiration imposes a lower limit of $0.020 \mathrm{mg} \mathrm{C} \mathrm{mg}^{-1}$ day $^{-1}$, with higher values representing a greater proportion of construction respiration. Despite their remarkable consistency across cultivars and seasons, these figures do not appear to be inevitable conclusions of model assumptions: removing the older half of the phytomer positions (7-12) from the Alto in autumn calculations increased the respiration rate from 0.024 to $0.028 \mathrm{mg} \mathrm{C} \mathrm{mg}^{-1}$ day $^{-1}$, while in Aberdart, removing phytomer positions 8-14 increased respiration rates from 0.024 to $0.028 \mathrm{mg} \mathrm{C} \mathrm{mg}^{-1} \mathrm{day}^{-1}$, reflecting a greater proportion of construction respiration. $\mathrm{C}$ requirements on a phytomer basis were calculated as the average of the summed construction costs and maintenance respiration for each phytomer. Alto required approximately $0.77 \mathrm{mg} \mathrm{C}$ phytomer $^{-1}( \pm 0.03)$ in spring, and $0.87 \mathrm{mg}( \pm 0.04)$ in autumn, while Aberdart had calculated $C$ requirements of $0.71 \mathrm{mg}$ phytomer $^{-1}( \pm 0.04)$ in spring, and $0.99 \mathrm{mg} \mathrm{C}$ phytomer $^{-1}$ $( \pm 0.03)$ in autumn.

\section{Discussion}

\subsection{Developing a Phytomer-Based Understanding of Root Birth, Growth and Senescence}

This work represents the first attempt to integrate plant architectural data, including estimates of photosynthetic C-gain with root mass and position to explore the $\mathrm{C}$ supply-demand kinetics of root growth and development. To achieve our goals, we used a combination of measured data and published values for tissue construction and maintenance costs. The model estimates $C$ demand at each position as a function of both maintenance respiration rates and root growth. Our results suggest strong seasonal effects on root growth rate as a result of differences in $C$ availability. In spring, the combined $\mathrm{C}$ costs increased at each phytomer position, reflected in root growth. In autumn, the modelled C demand at each position was relatively invariant, with a shift from growth to maintenance costs dominating over the youngest seven phytomer positions, while the $C$ demand at older phytomers was primarily due to maintenance respiration. In a previous study exploring the $C$ dynamics of root growth, Matthew and Kemball [28] found that ${ }^{14} \mathrm{CO}_{2}$ labelled ryegrass plants distributed photoassimilate in an approximately exponential pattern, with the youngest roots containing the most ${ }^{14} \mathrm{C}$, and increasingly older roots containing progressively less radiocarbon. It was postulated that this distribution was the result of differences in ${ }^{14} \mathrm{C}$ allocation to different root classes; however, an alternate explanation suggested by our model is that $C$ allocated to older roots was respired, while in younger roots it was fixed as biomass and could be measured.

In both seasons, the decrease in $C$ available by phytomer position was broadly linear, as a result of the approximately equal calculated $C$ requirements for each nodal position. In the spring, despite lower whole-plant photosynthesis, there was sufficient $C$ to support root growth at all phytomer positions. However, in the autumn experiment, our model suggests that the $C$ demand of roots was greater than the shoots' ability to supply photoassimilate. While the youngest roots clearly had sufficient $C$ to grow rapidly, it is likely that the oldest roots were unable to cover maintenance respiration costs, unless supplied additional $C$ by a daughter tiller [25]. Under such conditions, we expect older roots to undergo autophagy and senescence. Our model assumes a single $C$ cost of maintenance respiration, although it is plausible that maintenance respiration rates vary with root age or temperature. Little research has explored this possibility.

A key insight from this research is that whereas the number of leaf bearing phytomers in ryegrass is typically three-although it was up to ten in these experiments-the number of root bearing phytomers was much greater (up to 17 in the autumn experiment). This is a longer duration for the below ground root turnover cycle than the simultaneous, aboveground leaf turnover cycle. 


\subsection{Seasonal Effects}

The autumn plants were significantly larger and supported more roots than their spring counterparts. Our experiments were planned such that the day length of the first day in the spring experiment was identical to the final day of the autumn experiment, meaning that the plants accumulated similar numbers of daylight hours. However, the distribution of these hours was inverted between experiments, with the photoperiod increasing over the spring experiment, and decreasing over the autumn experiment. Although the plants were grown in a glasshouse, temperature may also have been an important factor, with long-term climatological data for the years 1980 to 2010 giving mean air temperatures of 8.6, 9.2 and $11.0^{\circ} \mathrm{C}$ for July through September (New Zealand spring), and 16.4, 13.6 and $11.4{ }^{\circ} \mathrm{C}$ for March through May (NZ autumn) [29] at the experimental location. We assume that differences in plant mass between seasons were due to seasonal factors; however, without re-running the experiment, we cannot rule out other possibilities, such as subtle differences in the hydroponic solution between experiments. Furthermore, our data was derived from two experiments using two cultivars within one yearly cycle, and caution should be exercised in the interpretation of our results. Although our plants would almost certainly show variation between years, we expect the patterns noted here would remain, irrespective of annual variability.

The phyllochron, and by extension the rhizochron, varied within each experiment, and were longer in spring than autumn. Leaf appearance rates suggest that the oldest phytomers in the autumn plants had significantly shorter phyllochrons than even the youngest phytomers in the spring plants. Spring plants produced seven phytomers (and hence seven leaves) over the modelling period, while in autumn Alto produced 12 and Aberdart 14 in a similar timeframe. These seasonal changes in the phyllochron are undoubtedly biologically real, and arise from the way the tiller axis architecture responds to changing environmental conditions over the two experiments. The phyllochron, and by extension the rhizochron, were short at the oldest root positions in autumn plants-these roots would have been produced toward the end of summer, when whole plant photosynthetic rates were presumably high. There was a greater period between root initiation at the newest positions as autumn turned to winter, and growth conditions became less favourable. In spring plants, this pattern was reversed, with the longest phyllochrons in the oldest phytomers, decreasing in younger positions, as environmental conditions improved. Similar to leaves, root appearance rates in ryegrass have been shown to be strongly influenced by both light and temperature, with reduced rates under low light or low temperature conditions [30].

Root turnover is a constant process of initiation, growth, and senescence. These processes happen simultaneously, with young roots growing while mature roots senesce. Our model demonstrates a seasonal shift in the balance between $C$ gain and demand, where gain exceeds demand in the spring, and demand exceeds gain in autumn. This ratio of $C$ gain to demand has been posited as an "architectural signal" [31], which varies throughout the year due to environmentally mediated changes in the phyllochron preceding changes in the rhizochron. During spring, our data shows that the phyllochron decreased as environmental conditions improved, with a greater number of leaves supporting fewer roots. This is postulated to lead to an increase in the number or roots produced per phytomer, or an increase in mean root mass. In autumn, where fewer leaves would be supporting a greater number of roots, we would expect the oldest roots to senesce due to $C$ insufficiency.

In this study, the majority of root growth occurred in the first 5-7 phytomer positions, both in spring and autumn plants, although given the longer phyllochrons in spring plants, the absolute growth rates differed greatly between seasons. Similarly, Yang et al. [18] showed a strong increase in the frequency of root formation in winter grown L. perenne over the first six phytomer positions. However, our plants exhibited a much higher number of leaves. The reason for this discrepancy is not clear but may be due to the removal of daughter tillers upon formation, or our use of hydroponic culture, while Yang et al. [18] grew their plants in a soil/sand mix and did not de-tiller their plants. Leaf senescence can be delayed by nutrient sufficiency, and it is plausible that our plants were more nutrient replete than in other experiments. 


\subsection{Cultivar Effects}

Fundamentally, the two cultivars exhibited very similar patterns of root growth and development despite differences in shoot morphology. This may relate to their architectural structure imposing a pattern of root initiation, growth and development which has more influence on plant morphology than the genetic differences between them. In terms of leaf area, Aberdart was significantly larger than Alto, and despite the lower measured photosynthetic rates, was calculated to contribute approximately $25-33 \%$ more $C$ to the roots (Table 1 ). However, similar root masses at each phytomer position were achieved by the two cultivars. Aberdart produced more phytomer positions over the modelled period in the autumn experiment, which may be due to its greater photosynthetic capacity. The phyllochron tended to be shorter in Aberdart than Alto, particularly in spring. Although our experiment includes only two cultivars and two seasons, and was completed under uniform culture conditions in a hydroponic system, meaning that due caution should be exercised, this suggests that in the absence of other influences, root growth per phytomer position may be relatively invariant in ryegrass, with changes in the phyllochron more important in determining total root biomass.

In the autumn experiment, Alto exhibited a greater range of phyllochron durations than Aberdart, suggesting a greater responsiveness to environmental conditions. The phyllochron, and by extension the rhizochron, was short at the oldest root positions in autumn plants-these roots would have been produced toward the end of summer, when whole plant photosynthetic rates were presumably high. There was a greater period between root initiation at the newest positions as autumn turned to winter, and growth conditions worsened. No relationship between phyllochron and root age was apparent in spring plants.

\subsection{Model Justification}

Although all models are necessarily simplifications, if they are to generate useful hypotheses they must have some correspondence to reality. Our root mass model assumes an exponential relationship rising to a maximum value. This model makes two main assumptions: (1) there exists a maximum root mass per phytomer position, (2) there exists a negative relationship between root mass and growth rate $\left(\mathrm{mg} \mathrm{day}^{-1}\right)$. The first assumption is reasonable where the system is considered to be in a steady state of root formation and maturation, but unlikely to be universally true in the field. Plausibly, a constant final root mass is an emergent property of the phyllochron and root growth rate, both of which are affected by plant $C$ status. Seasonal shifts in plant $C$ balance would be reflected in the number of root-bearing phytomers, with greater numbers in the autumn experiment. The second assumption suggests a tradeoff between maintenance respiration and growth; consumption of $C$ by maintenance respiration leads to a decrease in the available $C$ for growth. However, while this must hold true for the root system as a whole, it is unclear whether this relationship holds true across phytomer positions. Our model assumes that the daily growth rate of roots could be calculated as the difference in estimated root mass between adjacent phytomers divided by the phyllochron. This assumes a close relationship between leaf emergence and root initiation [18].

Our model used values of 0.4 and $0.24 \mathrm{mg} \mathrm{C} \mathrm{mg}^{-1} \mathrm{DW}$ as the $\mathrm{C}$ content and construction costs for root growth, and $0.02 \mathrm{mg} \mathrm{C} \mathrm{mg}^{-1} \mathrm{DW}$ day ${ }^{-1}$ for the maintenance respiration cost [26]. Amthor [32] cited data that agrees with these values; however, other studies have calculated lower values, with Pooter et al. [33] arriving at values between 5.5 and $8 \mathrm{mmol} \mathrm{O}_{2} \mathrm{~g}^{-1} \mathrm{DW}$. Assuming a C:O stoichiometry of 2:1, this would give values ranging from 0.13 to $0.19 \mathrm{~g} \mathrm{C} \mathrm{g}^{-1} \mathrm{DW}$ for construction respiration, or a total construction cost of 0.53 to $0.59 \mathrm{~g} \mathrm{C} \mathrm{g}^{-1} \mathrm{DW}$, compared with Robinson's value 0.64 . These lower values would be more important in the younger, actively growing, phytomers, and may decrease the higher values calculated at the first few phytomer positions. Rachmilevitch et al. [34] estimated a specific maintenance respiratory cost of approximately $1.2 \mathrm{mmol} \mathrm{O}_{2} \mathrm{~g}^{-1} \mathrm{DW}$ day $^{-1}$ for Agrostis plants grown at $20^{\circ} \mathrm{C}$. Given a respiratory quotient of 1.2, this would yield a daily maintenance cost of $0.017 \mathrm{~g} \mathrm{C} \mathrm{g}^{-1} \mathrm{DW}$, which is close to the value of $0.02 \mathrm{~g} \mathrm{~g}^{-1} \mathrm{DW}$ day ${ }^{-1}$ used here. 
Tiller $\mathrm{C}$ fixation was estimated from the mean of the photosynthetic rates of the five youngest leaves. For older leaves, this mean was multiplied by a weighting factor of 0.75 to account for reduced photosynthesis in older leaves. In grasses, new leaves are formed at the top of the canopy, meaning older leaves typically inhabit lower light environments, and exhibit lower photosynthetic rates ([35] and references therein). Although using a 0.75 weighting factor yields an imprecise estimate of tiller photosynthesis, it is likely to over-estimate rather than underestimate the photosynthetic activity of old leaves, and should be sufficiently realistic to gain a broad understanding of plant $C$ status. Changes in the weighting factor should have relatively little effect on photosynthetic estimates in spring plants, which averaged between 6.6 and 8.1 leaves, while in autumn, changes in the weighting factor would have a bigger influence given the greater number of leaves noted (Table 1). Root $C$ allocation was estimated at $15 \%$ of fixed $C$, in line with previous studies $[25,27]$. Changes in the weighting factor or root allocation would affect the quantity of $C$ available to the roots, although the general patterns identified by our model would remain the same.

Respiration rates are known to be affected by short-term changes in environmental temperature, but after an acclimation period may be relatively invariant [36], and seasonal shifts in temperature may have little effect on specific respiration rates. Root construction costs are generally thought to be unaffected by environmental temperature, given that the energetic requirements of cell division, etc., should not be variable. Scheurwater et al. [37] measured the rates of root respiration in a range of forage grass species, finding comparatively little variation between the nine species used. Only minor differences in growth and maintenance respiration values were noted between fast and slow-growing species, although ion uptake costs were calculated to be around three times higher in the slow growing Festuca ovina than the fast growing Dactylis glomerata. This comparative consistency between a wide range of species may give our model a relatively broad applicability. Across species, respiration rates scale isometrically with plant mass and $\mathrm{N}$ concentration, and are relatively unaffected by environmental factors, such as light, $\mathrm{N}$ availability, temperature and atmospheric $\mathrm{CO}_{2}$ levels [38], although this does not preclude variability within species to environmental conditions.

Specific root respiration rates decrease with plant age [34], which may be related to the proportion of the root system involved in active growth. In our experiment, the smaller spring roots were calculated to have higher specific respiration rates. Furthermore, removing the older half of the phytomer positions from the autumn datasets led to $17.5 \%$ and $18.3 \%$ increases in the calculated specific respiration rate in Alto and Aberdart respectively. Given that the metabolism of older roots is dominated by maintenance respiration, while the younger roots are actively growing, this may be unsurprising. The fraction of $\mathrm{C}$ used for growth was around $80 \%$ in spring but $70 \%$ in autumn plants, suggesting that the balance between new growth and maintenance changes with standing root mass. Our model assumes maintenance respiration rate to be broadly the same between roots of different ages. However, previous studies in grape rootstocks (Vitis rupestris $\times$ Vitis riparia) have shown significantly higher respiration rates in young roots, along with high rates of $\mathrm{N}$ influx [39], although it seems likely that longer lived roots of woody plants behave differently than grass roots.

Although our model has been developed in ryegrass, it should be broadly applicable to the majority of agronomically important temperate pasture grass species, given that they share the same phytomer-based morphology. An exponential increase to a maximum for root mass at successively older phytomer positions should be a broadly applicable assumption for grass species, although may vary between different groups (e.g., between cereal species and pasture species) due to differences in leaf longevity or initiation rates. Our model was developed under standard hydroponic conditions, where each root would have been subject to similar conditions, allowing us to observe the underlying patterns of root initiation and growth. However, in the field, local conditions such as nutrient patches or uneven water availability would cause changes in root growth patterns and $C$ allocation, complicating the patterns seen here. Similarly, our model is limited in dealing with only younger roots. Fitter [12] estimated the half-life of grass roots in Festuca ovina dominated turves at 50-60 days, although a small percentage of roots survived for two years or more. Despite these limitations, and the need to conduct 
measurements in a wider variety of species and conditions, we feel our model is able to yield important insight into the regulation of $C$ allocation within the root system of perennial grass plants.

In conclusion, we developed a phytomer-based model of root growth, which suggests an equal sharing of $C$ between roots of different ages. Our model suggests that photoassimilate use is split between maintenance respiration and the production of new biomass, with older root growth strongly constrained by their high $C$ requirements for maintenance. This model allowed us to reanalyze noted patterns of photoassimilate distribution in previous isotope labelling studies, emphasizing the importance of maintenance respiration in understanding root system development. The model provided evidence in favor of the "architectural signal" hypothesis as the mechanism underlying changes in root mass under changing environmental conditions. Overall, this work provides novel insights as to how the distinctive phytomer-based architecture in perennial ryegrass, a member of the Poaceae, confers specific properties to patterns of plant growth and development.

Author Contributions: Conceptualization, A.H.K.R. and C.M.; Data curation, A.H.K.R. and L.J.I.; Formal analysis, L.J.I.; Investigation, A.H.K.R. and E.K.; Methodology, A.H.K.R. and L.J.I.; Project administration, C.M.; Supervision, C.M.; Writing-original draft, A.H.K.R. and L.J.I.; Writing-review \& editing, A.H.K.R., E.K. and C.M.

Funding: Doctoral research of A.H.K.R. was supported by a 'Massey University Vice-Chancellor's Doctoral Scholarship' and study leave from Bangladesh Agricultural University. A financial grant from the T.R. Ellett Agricultural Research Trust during preparation of this manuscript is gratefully acknowledged.

Acknowledgments: We thank Steven Ray, Lindsay Silva and Lesley Taylor for their assistance with plant culture and Chris Rawlingson for his help with the photosynthesis measurements.

Conflicts of Interest: The authors declare no conflict of interest.

\section{References}

1. Skinner, R.H.; Nelson, C.J. Elongation of the grass leaf and its relationship to the phyllochron. Crop Sci. 1995, 35, 4-10. [CrossRef]

2. Durand, J.L.; Schaufele, R.; Gastal, F. Grass leaf elongation rate as a function of developmental stage and temperature: Morphological analysis and modelling. Ann. Bot. 1999, 83, 577-588. [CrossRef]

3. Robinson, D. Scaling the depths: Below-ground allocation in plants, forests and biomes. Funct. Ecol. 2004, 18, 290-295. [CrossRef]

4. Parsons, A.J.; Robson, M.J. Seasonal changes in the physiology of S24 perennial ryegrass (Lolium perenne L.). 2. Potential leaf and canopy photosynthesis during the transition from vegetative to reproductive growth. Ann. Bot. 1981, 47, 249-258. [CrossRef]

5. Parsons, A.J.; Robson, M.J. Seasonal changes in the physiology of S24 perennial ryegrass (Lolium perenne L.). 4. Comparison of the carbon balance of the reproductive crop in spring and the vegetative crop in autumn. Ann. Bot. 1982, 50, 167-177. [CrossRef]

6. Robson, M.J.; Jewiss, O.R. A comparison of British and North African varieties of tall fescue (Festuca arundinacea). III. Effects of light, temperature, and day length on relative growth rate and its components. J. Appl. Ecol. 1968, 5, 191-204. [CrossRef]

7. Fulkerson, W.J.; Donaghy, D.J. Plant-soluble carbohydrate reserves and senescence-Key criteria for developing an effective grazing management system for ryegrass-based pastures: A review. Aust. J. Exp. Agric. 2001, 41, 261-275. [CrossRef]

8. Fitter, A.H.; Self, G.K.; Brown, T.K.; Bogie, D.S.; Graves, J.D.; Benham, D.; Ineson, P. Root production and turnover in an upland grassland subjected to artificial soil warming respond to radiation flux and nutrients, not temperature. Oecologia 1999, 120, 575-581. [CrossRef] [PubMed]

9. Lattanzi, F.A.; Schnyder, H.; Thornton, B. The sources of carbon and nitrogen supplying leaf growth. Assessment of the role of stores with compartmental models. Plant Physiol. 2005, 137, 383-395. [CrossRef] [PubMed]

10. Lehmeier, C.A.; Lattanzi, F.A.; Schaufele, R.; Wild, M.; Schnyder, H. Root and shoot respiration of perennial ryegrass are supplied by the same substrate pools: Assessment by dynamic ${ }^{13} \mathrm{C}$ labeling and compartmental analysis of tracer kinetics. Plant Physiol. 2008, 148, 1148-1158. [CrossRef] [PubMed] 
11. Carbone, M.S.; Trumbore, S.E. Contribution of new photosynthetic assimilates to respiration by perennial grasses and shrubs: residence times and allocation patterns. New Phytol. 2007, 176, 124-135. [CrossRef] [PubMed]

12. Fitter, A.H.; Graves, L.D.; Wolfenden, J.; Self, G.K.; Brown, T.K.; Bogie, D.; Mansfield, T.A. Root production and turnover and carbon budgets of two contrasting grasslands under ambient and elevated atmospheric carbon dioxide concentrations. New Phytol. 1997, 137, 247-255. [CrossRef]

13. Matthew, C.; Mackay, A.D.; Robin, A.H.K. Do phytomer turnover models of plant morphology describe perennial ryegrass root data from field swards? Agriculture 2016, 6, 28. [CrossRef]

14. Gallardo, M.; Turner, N.C.; Ludwig, C. Water relations, gas exchange and abscisic acid content of Lupinus cosentinii leaves in response to drying different proportions of the root system. J. Exp. Bot. 1994, 45, 909-918. [CrossRef]

15. Robin, A.H.K.; Matthew, C.; Uddin, M.J.; Bayazid, K.N. Salinity-induced reduction in root surface area and changes in major root and shoot traits at the phytomer level in wheat. J. Exp. Bot. 2016, 67, 3719-3729. [CrossRef] [PubMed]

16. Robin, A.H.K.; Uddin, M.J.; Bayazid, K.N. Polyethylene Glycol (PEG)-treated hydroponic culture reduces length and diameter of root hairs of wheat varieties. Agronomy 2015, 5, 506-518. [CrossRef]

17. Robinson, D. The responses of plants to non-uniform supplies of nutrients. New Phytol. 1994, 127, 635-674. [CrossRef]

18. Yang, J.Z.; Matthew, C.; Rowland, R.E. Tiller axis observations for perennial ryegrass (Lolium perenne) and tall fescue (Festuca arundinacea): Number of active phytomers, probability of tiller appearance, and frequency of root appearance per phytomer for three cutting heights. N. Z. J. Agric. Res. 1998, 41, 11-17. [CrossRef]

19. Crush, J.R.; Nichols, S.N.; Ouyang, L. Adventitious root mass distribution in progeny of four perennial ryegrass (Lolium perenne L.) groups selected for root shape. N. Z. J. Agric. Res. 2010, 53, 193-200. [CrossRef]

20. Anonymous. Pasture Manual 2006-The Complete Guide to Pasture Technology; New Zealand Agriseeds Limited: Christchurch, New Zealand, 2005.

21. Downing, T.T.W.; Gamroth, M.J. Nonstructural Carbohydrates in Cool-Season Grasses; Special Report 1079-E; Oregon State University Extension Service: Corvallis, OR, USA, 2007.

22. Hoekstra, N.J.; Struik, P.C.; Lantinga, E.A.; Schulte, R.P.O. Chemical composition of lamina and sheath of Lolium perenne as affected by herbage management. NJAS 2007, 55, 55-73. [CrossRef]

23. Robin, A.H.K.; Matthew, C.; Crush, J. Time course of root initiation and development in perennial ryegrass-A new perspective. Proc. N. Z. Grassl. Assoc. 2010, 72, 233-239.

24. Bryson, R.J.; Paveley, N.D.; Clark, W.S.; Sylvester-Bradley, R.; Scott, R.K. Use of in-field measurements of green leaf area and incident radiation to estimate the effects of yellow rust epidemics on the yield of winter wheat. Dev. Crop Sci. 1997, 25, 77-86. [CrossRef]

25. Carvalho, D.D.; Irving, L.J.; Carnevalli, R.A.; Hodgson, J.; Matthew, C. Distribution of current photosynthate in two Guinea grass (Panicum maximum Jacq.) cultivars. J. Exp. Bot. 2006, 57, 2015-2024. [CrossRef] [PubMed]

26. Robinson, D. Root proliferation, nitrate inflow and their carbon costs during nitrogen capture by competing plants in patchy soil. Plant Soil 2001, 232, 41-50. [CrossRef]

27. Parsons, A.J.; Robson, M.J. Seasonal changes in the physiology of S24 perennial ryegrass (Lolium perenne L.). 3. Partitioning of assimilates between root and shoot during the transition from vegetative to reproductive growth. Ann. Bot. 1981, 48, 733-744. [CrossRef]

28. Matthew, C.; Kemball, W.D. Allocation of carbon-14 to roots of different ages in perennial ryegrass (Lolium perenne L.). In Proceedings of the XVIII International Grassland Congress, Calgary, AB, Canada, 8-17 June 1997.

29. New Zealand National Institute of Water and Atmospheric Research. Available online: https:/ / www.niwa. co.nz/education-and-training/schools/resources/climate (accessed on 30 May 2018).

30. Hunt, W.F.; Thomas, V.J. Growth and developmental responses of perennial ryegrass grown at constant temperature II. Influence of light and temperature on leaf, tiller and root appearance. Aust. J. Plant Physiol. 1985, 12, 69-76. [CrossRef]

31. Matthew, C.; Yang, J.Z.; Potter, J.F. Determination of tiller and root appearance in perennial ryegrass (Lolium perenne) swards by observation of the tiller axis, and potential application in mechanistic modelling. N. Z. J. Agric. Res. 1998, 41, 1-10. [CrossRef] 
32. Amthor, J.S. The role of maintenance respiration in plant growth. Plant Cell Environ. 1984, 7, 561-569. [CrossRef]

33. Poorter, H.; van der Werf, A.; Atkin, O.K.; Lambes, H. Respiratory energy requirements of roots vary with the potential growth rate of a plant species. Physiol. Plant 1991, 83, 469-475. [CrossRef]

34. Rachmilevitch, S.; Lambers, H.; Huang, B. Root respiratory characteristics associated with plant adaptation to high soil temperature for geothermal and turf-type Agrostis species. J. Exp. Bot. 2006, 57, 623-631. [CrossRef] [PubMed]

35. Gastal, F.; Lemaire, G. N uptake and distribution in crops: An agronomical and ecophysiological perspective. J. Exp. Bot. 2002, 53, 789-799. [CrossRef] [PubMed]

36. Gunn, S.; Farrar, J.F. Effects of a $4{ }^{\circ} \mathrm{C}$ increase in temperature on partitioning of leaf area and dry mass, root respiration and carbohydrates. Funct. Ecol. 1999, 13, 12-20. [CrossRef]

37. Scheurwater, I.; Cornelissen, C.; Dictus, F.; Welschen, R.; Lambers, H. Why do fast- and slow-growing grass species differ so little in their rate of root respiration, considering the large differences in rate of growth and ion uptake? Plant Cell Environ. 1998, 21, 995-1005. [CrossRef]

38. Reich, P.B.; Tjoelker, M.G.; Machado, J.-L.; Oleksyn, J. Universal scaling of respiratory metabolism, size and nitrogen in plants. Nature 2006, 439, 457-461. [CrossRef] [PubMed]

39. Volder, A.; Smart, D.R.; Bloom, A.J.; Eissenstat, D.M. Rapid decline in nitrate uptake and respiration with age in fine lateral roots of grape: Implications for root efficiency and competitive effectiveness. New Phytol. 2005, 165, 493-502. [CrossRef] [PubMed]

(C) 2018 by the authors. Licensee MDPI, Basel, Switzerland. This article is an open access article distributed under the terms and conditions of the Creative Commons Attribution (CC BY) license (http://creativecommons.org/licenses/by/4.0/). 